\title{
Dissociative Amnesia
}

National Cancer Institute

\section{Source}

National Cancer Institute. Dissociative Amnesia. NCI Thesaurus. Code C94328.

A disorder characterized by a retrospective gap in memory of important personal

information, usually of a traumatic or stressful nature; the memory loss far exceeds

ordinary forg etfulness and is not the result of substance use or the consequence of a medical condition. 